\title{
Post-Partum Uterine Eversion and its Management in A Doe: A Case Report
}

\author{
Shriya Gupta*, Amit Sharma and Madhumeet Singh \\ College of Veterinary and Animal Sciences, Himachal Pradesh Agricultural University, India
}

Submission: October 25, 2018; Published: November 05, 2018

*Corresponding author: Shriya Gupta, Department of veterinary Gynaecology and Obstetrics, College of Veterinary and Animal Sciences, Himachal Pradesh Agricultural University, Palampur, Himachal Pradesh 176062, India

\begin{abstract}
A case of uterine prolapse in 3 years old non-descript doe is reported. Assessment of prolapsed mass was done under epidural anesthesia. Uterus was cleaned with potassium permanganate solution and Lignocaine jelly and Soframycin was applied on the mass. Oxytocin and broadspectrum antibiotics were administered intramuscularly in recommended doses. Aim of present study was to highlight the management of uterine prolapse in doe.
\end{abstract}

Keywords: Doe; Epidural anesthesia; Lignocaine; Prolapsed mass

\section{Introduction}

Uterine prolapse is an eversion of the uterus which turns inside out as it passes through the vagina generally occurs immediately after or few hours of parturition when the cervix is open and lacks tone [1]. Most common post-partum complication observed in cows and ewes and less commonly in does [2]. Uterine prolapse in goats may be complete with both the horns protruding out from vulva or may be limited to the uterine body [3]. Etiology of uterine prolapse is unknown, but many factors have been associated with it $[1,4]$. These includes poor uterine tone, increased straining caused by pain or discomfort after parturition, by excessive traction at assisted parturition or by the weight of retained fetal membranes, conditions such as tympany and excessive estrogen content in feed leads to increased intraabdominal pressure leading to uterine prolapse. Prolapse that occur more than 24 hours post-partum is extremely rare and is complicated by partial closure of the cervix, making replacement difficult or even impossible [5]. Immediately after prolapsed occurs the tissues appear almost normal, but with passage of time becomes enlarged and edematous. Some animals may develop hypovolaemic shock secondary to internal blood loss, laceration of the prolapsed organ or incarceration of abdominal viscera [6]. Success of treatment depends on the type of case, duration of case, degree of damage and contamination. Present study envisages the management of uterine prolapse in goat.

\section{Case History}

An adult non-descript doe was presented to the Teaching Veterinary Clinical complex Palampur, India with complaint of hanging mass from vulva (Figure 1). Owner reported that doe delivered two female kids at full term of gestation and subsequently about 3hour uterine prolapse occurred. At the time of observation, the animal was dull and depressed. The clinical examination of the animal showed pale visible mucus membranes, body temperature $990 \mathrm{~F}$, heart rate $128 / \mathrm{min}$ and respiratory rate $22 / \mathrm{min}$. Clinico-gynaecological examination revealed, edematous everted uterine mass soiled with dirt, feces and straw.

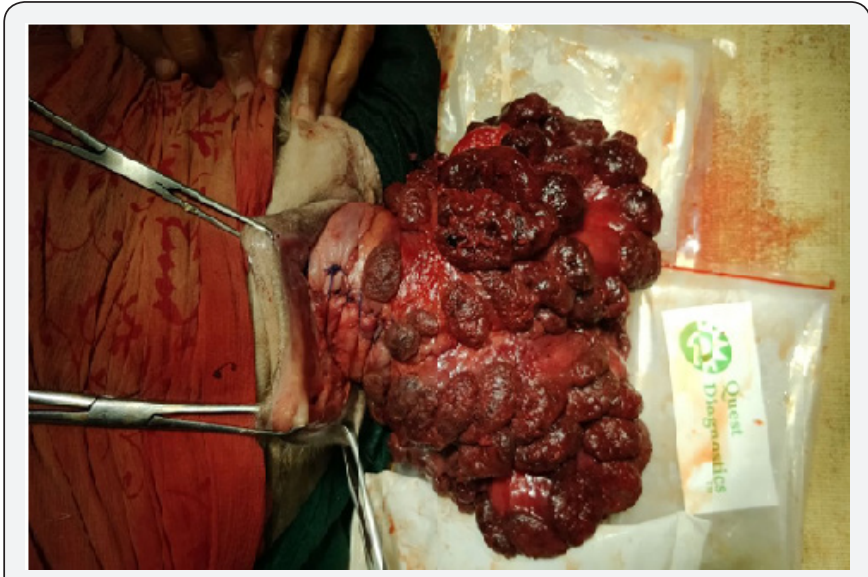

Figure 1: Prolapsed mass.

Result and Discussion

The goat was administered $2 \mathrm{ml}$ of $2 \%$ Lignocaine hydrochloride (LOX®, Neon Labs, India) at first coccygeal space 
to attain epidural anesthesia. Prolapsed uterus was gently washed and disinfected with potassium permanganate solution (1:1000 dilution) followed by application of icepacks to reduce edema and volume of the mass. Cervical lacerations were sutured using simple interrupted suture (Chromic catgut no.2). Prolapsed mass was washed with cold water and lubricated with Lignocaine jelly (Lignox®, Neon Labs, India) and Soframycin ointment (Soframycin ${ }^{\circledR}$, Sanofi, India). By applying adequate palm pressure, prolapsed mass was pushed inside the vulva slowly with alternate pushing of upper and lower surfaces and simultaneously elevating the hindquarters of the animal.

Further, pressure was applied to push the organ forward to abdominal cavity ensuring the proper repositioning of the uterus into its original position. No vulval retention suture was applied. The animal was administered Inj. Calcium borogluconate (100 $\mathrm{ml}$, slow i/v), Inj. DNS (400 ml, i/v), Inj Haemaccel $(100 \mathrm{ml}$, $\mathrm{i} / \mathrm{v}$ ), Ceftriaxone (200 mg, i/m), Inj. Oxytocin (10 I.U, i/m), Inj Texableed $(5 \mathrm{ml}, \mathrm{i} / \mathrm{m})$, Inj. Flunixin meglumine $(1.5 \mathrm{ml}, \mathrm{i} / \mathrm{m})$, Inj. Belamyl (2ml, i.m). Antibiotics and Anti-inflammatory was continued for three days. Haematinic mixture @1.5g once a day was given orally. The treatment was continued for three days and doe recovered uneventfully.

Prolapse of uterus normally occurs during third stage of labor[3] and in small animals, complete prolapse of both the uterine horns is usual [4]. Prolapse is reported to occur due to poor body condition, lack of uterine tone, retension of placenta and irritation in birth canal during parturition [1]. The common complications of uterine prolapse may be haemorrhages, shock, septic metritis, suckling problems, infertility and death. Uterine prolapse is an emergency, which needs immediate proper treatment, otherwise interference in the blood supply of prolapsed mass may resulted into edema, cyanosis and later may develop into gangrene [7]. Sometimes in delayed cases, partial contraction of cervix interferes with repositioning, resulting in reoccurrence of prolapse [8].

Prompt treatment of the condition is essential to prevent toxemia and death of the animal. Possible cause of death of animal even after treatment could be hypovolaemic shock as a result of blood loss due to lacerations in prolapsed uterus. Animals with uterine prolapse treated promptly recovers without complication while delay in treatment could result in death of the animal in a matter of hour or so from internal hemorrhage caused by the weight of the organ which tears the mesovarium and artery [3]. Since the animals suffering from the uterine prolapse are hypocalcaemic [5], therefore calcium borogluconate should be administered. Broad spectrum antibiotics after replacement of the prolapsed mass prevent secondary bacterial infection [9]. Shock, hemorrhage and thrombo-embolism are potential sequel of prolonged prolapsed [3]. However, animal can conceive again without problem if managed properly [10].

\section{Conclusion}

Successful management of post-partum uterine prolapse was done in doe.

\section{References}

1. Hanie EA (2006) Prolapse of the Vaginal and Uterus: Text Book of Large Animal Clinical Procedures for Veterinary Technicians. Elsevier, Mosby, St.Louis, MO, USA.

2. Sahadev A, Suchitra BR, Renukaradhya GJ (2014) Management of uterine eversion in ewe. Intas- polivet 15(11): 448-449.

3. Noakes DE, Perkinson TJ, England GCW (2009) Post Parturient Prolapse of the Uterus. In Arthur's Veterinary Reproduction and Obstetrics, Saunders, UK.

4. Jackson PG (1995) Post parturient problems in large animals Handbook of Veterinary Obstetrics, $\left(2^{\text {nd }} e d n\right)$, Elsevier Saunders, UK.

5. Fubini SL, Ducharme GN (2006) Surgical Conditions of the Post-Partum Period in Text Book of Farm Animal Surgery. Saunders, Elsevier, St.Louis, MO, USA.

6. Potter $\mathrm{T}$ (2008) Prolapse of the Uterus in the Cow. UK Veterinary Journal 13: 1-3.

7. Kapadiya PS, Chauhan PM, Nakhashi HC, Sharma VK, Sutaria TV (2015) Recurrent post-partum uterine prolapse in a primiparous Mehsana buffalo-A case report. Journal of Livestock 6:109-112.

8. Srinivas G, Rajashri M and Ramachandra Reddy K (2014) Surgical management of complete postpartum uterine prolapse in a doe. Intaspolivet 15(2): 438-439.

9. Kumar AS (2014) Clinical management of postpartum total uterine prolapsed following excessive traction during delivery of kid in a nondescript goat. Journal of Agriculture and Veterinary Sciences, $7(10)$ 9-11.

10. Pothiappan P, Sureshkumar R, Vijaykumar H, Rao DJ (2013) Postpartum uterine prolapse in non-descriptive doe and its management. Indian Veterinary Journal 90: 67-68.

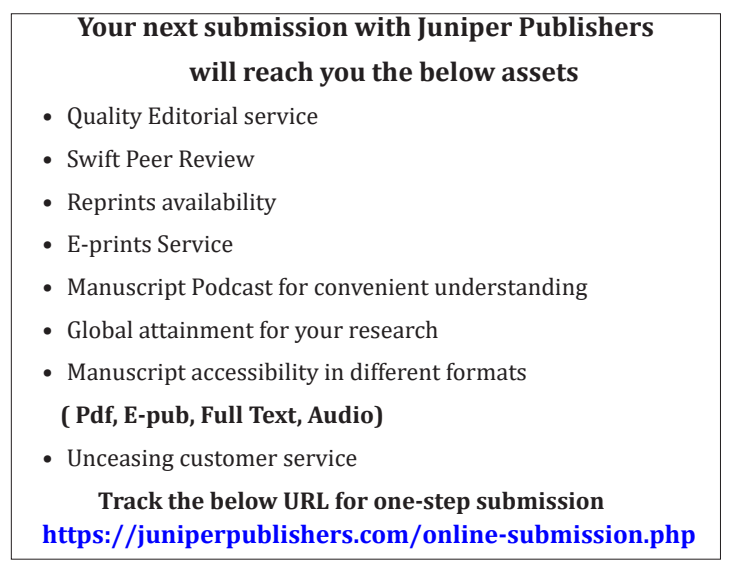

